Island Studies Journal, Vol. 4, No. 1, 2009, pp. 85-98

\title{
Islands of Astronomy
}

Godfrey Baldacchino

Canada Research Chair (Island Studies)

University of Prince Edward Island, Canada

gbaldacchino@upei.ca

and

Alexander Gatt

Institute for Astronomy and Astrophysics

University of Malta, Malta

alex_gatt@onvol.net

\begin{abstract}
A global review of islands and their connections with astronomy throughout history up to the contemporary times suggests eight compelling, distinct yet interlocking reasons why islands have been and remain so important to astronomy and astronomers. Islands constitute favourable locations for various types of astronomy-related activities: from tracking satellites and monitoring significant celestial events, to providing exceptional locations to jurisdictions with mandated dark and unpolluted skies. They appeal for their favourable longitude and (especially southern) latitude, as well as for their disposition towards the conditions that the scientific community may expect in an ideal world: relatively clear viewing conditions from a secure, self-contained platform that is, however, endowed with connectivity. This article is written as a contribution to the International Year of Astronomy (2009).
\end{abstract}

Keywords: astronomy, islands, latitude, longitude, Malta, NASA, Tycho Brahe

(C) 2009 - Institute of Island Studies, University of Prince Edward Island, Canada

\section{Introduction}

The year 2009 has been selected as the International Year of Astronomy: it is the $40^{\text {th }}$ anniversary of the first manned moon landing (1969) and the $400^{\text {th }}$ anniversary of the development and use of the telescope as an astronomical instrument (1609). This designation has sparked a commendable spate of research on this science. We are herewith providing our own contribution to this literature with a paper that considers the contribution and connection of islands to astronomy.

We do so primarily because we are motivated by a number of inter-related reasons. Although with very different educational and professional paths, the co-authors of this paper continue a long-standing friendship which took off three decades ago, thanks to their shared passion for astronomy; in 1978, they took the initiative to set up and launch the 
Students' Astronomical Circle, an amateur astronomy organization based at the University of Malta, in Malta. Moreover, they are both very much aware that, being Maltese, they are citizens of a rather small island state, yet one which has made its own valid contribution to the science and study of astronomy over many decades, and about which more will be said below. The international year of astronomy was the catalyst that spurred the co-authors to first discuss the feasibility of this project in January 2008; and then to put pen to paper, trying to develop a more organized and informed appreciation of the connection between islands and astronomy: two, typically separate, subjects of inquiry with what, at first sight, might appear to be very limited connections.

One of the co-authors (GB) is, since 2003, the Canada Research Chair in Island Studies at the University of Prince Edward Island, Canada; and so a curiosity to extend the understanding of the relationship between islands and astronomy beyond the authors' native land was a natural intellectual curiosity.

Moreover, as the authors of this paper, we are not interested in a casual or spurious link between islands and astronomy. Ours is an interest beyond coincidences and in the influence and consequences of islandness as an intervening variable: that is, the manner in which the island nature and/or location of a specific place contributes that special characteristic or advantage to the pursuit of astronomical tasks.

Finally, we deliberately refrain from drawing ourselves into an epistemological discussion as to what is an island. We could have entertained debates about the upper and lower limits to the size of an island; but then these would have been digressions to the overall thrust of this brief, mainly descriptive, paper. Nor do we engage with an understanding of Planet Earth as an island in space: a significant development of our understanding of our planet that has probably only emerged widely since the Space Age and our recently found ability to be able to observe the Earth from space (Cosgrove, 2001). Instead, we work with conventional definitions. These assume, for example, that Greenland is the world's largest island, and that Australia is the world's smallest continent.

We start our paper with a brief outline of the significance that Malta itself has played throughout the ages to the evolution of humankind's understanding of the heavens. From this review, we tease out specific details that speak to the condition of islandness and use this to launch into a global search that identifies eight distinct yet interrelated patterns of the significance of islands for astronomy.

\section{The Malta Connection}

Malta's contribution to the study of Astronomy is nothing short of millenary. The Islands' link with the science of the heavens is likely to date back at least 5,500 years. Many of the Copper Age Megalithic Temples that straddle the archipelago, including the world's oldest free-standing stone structures ${ }^{1}$, have a likely alignment with the sun's position at the spring and autumnal equinox (Bonanno \& Mintoff, 1997). In 1852, and again over 1861-5,

\footnotetext{
${ }^{1}$ The citation in the Guinness Book of Records states: "The oldest free standing structures in the world are now believed to be the megalithic temples at Ġgantija in Gozo [Malta] - from 3,600 B.C."
} 
William Lassell - who would later become President of the Royal Astronomical Society in Britain (1870-1872) - undertook observations from Tigné Point, in Malta. In his latter period, Lassell used what was then the largest movable reflecting telescope in the world (with a $116 \mathrm{~cm}$, or 48 -inch, mirror) and with which, assisted by Albert Marth, he made fresh discoveries in the Trapezium of the Orion Nebula and of around 600 other gaseous nebulae (Micallef, 1981; Lanfranco, 2005). The Leonid meteor storm of 1866 was very well documented from the Maltese Islands (Galea, 1994). Meticulous sunspot observations from Malta, by Tony Tanti and Frank Ventura, have led to the establishment of a sunspot quality index and count (e.g. Ventura \& Tanti, 1999). These and other episodes are well documented in such scholarly works as Agius \& Ventura (1980), Micallef (1992) and Ventura (2002).

\section{Looking for Patterns}

Moving beyond the specific case of Malta, one is quickly struck with a long list of seemingly disparate episodes of islands and their contributions to astronomy. Of course, some historic events may have occurred as they did on islands by mere happenstance: as, for example, when the monk Giuseppe Piazzi discovered the first asteroid, named Ceres, on January 1, 1801 from Palermo, on the island of Sicily. While we are interested in the listings for their own sake, we are also intrigued by their contents and wish to explore these records in some greater detail. In so doing, we hope to establish some general patterns of commonality: a 'signature' that may connect islandness, and any of its associated characteristics, to the study of astronomy.

One promising lead into this investigation is to look at yet another event that features Malta: the Solar Research Station set up by the University of Cambridge, UK, in Rabat, Malta, in the 1960s. This is because a document exists which actually traces the rationale behind the research team's eventual decision to transport and base their sophisticated equipment on the island (von Klüber, 1968).

\section{Favourable Locations and Conditions}

The main motivation for the Cambridge scientific team to consider Malta as their base was to "obtain good astronomical observations [requiring] ... more favourable climatic conditions" (ibid.: 479) than those pertaining to such places as the United Kingdom and Continental Europe. The Malta site was eventually selected because, apart from a "good sky" - confirmed by "uninterrupted sunshine" statistics - the island enjoyed political stability, had the advantage of being within the sterling (British Pound) area, and boasted an excellent passenger and freight service to and from London, then just 4 hours' of air travel distant. Interestingly, other locations considered before the final decision was taken included Nice, Mallorca, Sicily, Crete, Cyprus and Rhodes... all of which, except Nice, are Mediterranean islands. The researchers were obviously motivated by practical considerations. These would especially include the ability to identify a safe, not so distant and decent observing site that would be relatively free of light pollution, and sufficiently clear of built-up areas; and yet accessible to air and port facilities. Well connected and less 
heavily populated settlements thus qualify: many such places are well represented on islands.

The drive to locate and exploit clear skies is becoming increasingly exasperating to astronomers with the expansion of urban settlements, industrialization and widespread electrification, to the extent that we have today various 'dark sky' campaigns in many major cities ${ }^{2}$. So too is the problem of the pollution, opacity and the variable refractive index of the air column: astronomical observations at sea level have to contend with what is effectively an additional dirty and uneven lens some $320 \mathrm{~km}$ (200 miles) thick. Once again, islands score highly as preferential locations which are physically removed from the impacts of high populations (including smog and artificial lights); those with high altitude locations - such as mountain tops - become even more preferred, thanks to the ability to eliminate much atmospheric interference in observational clarity. For such reasons, some of the world's great telescopic sites today are located on the higher slopes of island locations. The two locations of the European Northern observatory - on Tenerife and La Palma, in the Spanish Canary Islands - benefit from the "excellent quality of the sky" which is determined and protected by law, since the two sites have constituted "astronomy reserves" since 1979. They are currently home to telescopes and other instruments belonging to 60 scientific institutions from 17 different countries (e.g. Murdin, 1985).

Meanwhile, another large collection of astronomical equipment and facilities rests on the crest of the dormant Mount Haleakala volcano, which rises 3,040 metres (10,023 feet) above sea level on the island of Maui, Hawai'i. Neighbouring Big Island of Hawai'i has an additional 14 observatories on the slopes of dormant Mauna Kea volcano, which rises 4,180 metres $(13,796$ feet) above sea level.

Tracking stations stretching from Cape Canaveral in Florida to the Indian Ocean made up the US Air Force Eastern Test Range, once dubbed the largest shooting gallery in the world. Renamed The Eastern Range in 1960, it included 13 major stations and some 90 outlying sites. These included ground stations on the islands of Antigua (Antigua and Barbuda), Ascension, at Argentia, Newfoundland (Canada), on Grand Bahama and Eleuthera (Bahamas), Fernando de Noronha (Brazil), Grand Turk (Turks and Caicos), Mahé (Maldives), Mayaguez (Puerto Rico) and St Lucia (Patrick Air Force Base, 2008).

In the area of non-visual astronomy, another island tops the charts. The unincorporated US Territory of Puerto Rico, in the Caribbean, hosts the world's largest, single-unit (even if hardly mobile) radio-radar telescope at Arecibo. The observatory is operated by Cornell University under a cooperative agreement with the US National Science Foundation. The Arecibo telescope is distinguished by its enormous size: the main collecting dish is 305 metres in diameter, constructed inside the depression left by a karst sinkhole. At $18^{\circ} 15^{\prime}$ North, Puerto Rico's location near the equator allows Arecibo to view all the planets in the solar system and large parts of both the northern and southern stellar hemisphere. Earlier, Puerto Rico had also been the base site of a number of observations of the transit of Venus.

\footnotetext{
${ }^{2}$ See International Dark Skies Association website at: http://www.darksky.org/mc/page.do. Ironically, a dark skies campaign is also active in Malta.
} 
A Spanish expedition led by Tómas de Azcárate set up an equatorial telescope and a transit instrument in the Arsenal of San Juan, the island's capital. They observed all contacts for the 1882 event, except for the external contact at egress, because they had to change the eye-piece at the very moment.

\section{The Absence of Indigenous Populations}

A totally different set of reasons and justifications has attracted other major investment in observational equipment, this time on the island of Ascension, which is today a United Kingdom Overseas Territory, located on the mid-Atlantic ridge. The rugged island has no indigenous human population: all the 'residents' are actually employees of Ascension's main industry: telecommunications servicing the military. It is US military interests which cite interference - that largely explain the denial of the 'right to abode' and refusal to open up the island to 'non-residents'. The island has served for many years as a military installation: it is the location of the ultra-modernized US-run Wideawake airfield, a hub for telephone and radio communications as well as a base for satellite tracking stations, including one operated by the European Space Agency for its Ariane spacecraft and a now defunct NASA station. Royle (2001: 54) reminds us that NASA used this base on Ascension Island as a tracking station for the Apollo Moon landings. Cable and Wireless tracks Ariane rockets soon after lift-off from French Guyana: as the latter lift off eastwards across the Atlantic, they can be monitored (for some six and a half minutes) only from Ascension (also CSC, 2005).

So, unlike mainlands, islands can be uninhabited, and kept that way: any residents can be denied residency or citizenship rights. Indeed islands, smaller ones in particular, lend themselves to near absolute human domination. They can be bought, sold, leased or bequeathed to special individuals, who can then transform them in accordance with their interests or whims, noble though these may be. It was in such circumstances, in 1576, that Frederick II, King of Denmark, allocated the island of Hven (also known as Ven, located between Denmark and Sweden, and now part of Sweden) as a 'fief' to astronomer Tycho Brahe as his home and base for his many scientific activities. This island, and Uraniborg castle in particular, was a prototype fully-integrated research facility, and a research centre of the highest order for its time. Tycho's plans involved considerable social upheaval on Hven, however. The project drafted the local peasants and fishers as cheap construction labour - "harnessed in the service of science" - for at least 8 years, and they were certainly not amused (Christianson, 1999: 43; also reviewed in Mosley, 2001). Tycho acted very much as the undisputed 'Lord of Uraniborg' (Thoren, 1990):

"[H]e aimed to restructure the production of Hven in order to support a superstructure of scholars, scientists and servants" (Christianson, 1999: 37).

Tycho's behaviour confirms the observation by Grant McCall (1996: 1-2): “continentals covet islands ... while islanders themselves and their way of seeing things are not much appreciated". This observation will also inform the plight of another group of islanders, the Chagossians, about whom more is said below. 


\section{Beyond Continental Longitudes and Latitudes}

Another set of reasons which make islands attractive to astronomers is that they occupy portions of the globe that lie beyond continental latitudes and longitudes. The continental masses cover just some $17 \%$ of the world's surface area. Islands are scattered over much of the remaining oceanic four-fifths of the globe (Depraetere \& Dahl, 2007). This is especially so for the Earth's southern hemisphere which contains less than a third of the land area that is enjoyed by its Northern counterpart (Tegg \& Curtis, 1829: 64) ${ }^{3}$. As a result, islands come in handy here in two particular ways.

First, for any celestial event requiring continuous, round-the-clock monitoring, the geographical location of islands is crucial. Although the advent of space telescopes may have somewhat dampened this condition, one field where this advantage remains especially useful is that of amateur meteor watching. The compilation of zenithal hourly rates that report meteor shower or sporadic meteor activity is so much more robust when the raw data is provided systematically across all the world's time zones - some of which are only populated by islanders.

Second, far-flung islands tend to lend themselves as more suitable locations for the observation of exceptional celestial events which may not be fully or conveniently visible from continental sites. One such rare occurrence is the transit of planet Venus across the sun's disc as seen from Earth. This is among the rarest of planetary alignments; only seven such events have occurred since the invention of the telescope $(1631,1639,1761,1769$, 1874, 1882 and 2004; next one due in 2012). The 1761 event was mostly missed due to inclement weather; and so Captain James Cook was dispatched to Tahiti, French Polynesia, to observe and record the details of the 1769 event. Cook and his party did record the transit when it happened on June 3. However, on the day of the transit, the log entry of naturalist Joseph Banks, who was accompanying Cook, consisted of just 622 words, of which fewer than 100 concern Venus. For some still unknown reasons, data from two other transit observing stations on Tahiti were not included in Cook's eventual full report (Orchiston, 2004: 60). Disappointment with what today is known as the 'black drop effect' may afford some, but not a complete, explanation.

In 1874, at the Royal Alfred Observatory, a meteorological station at Pamplemousses on the island of Mauritius, Charles Meldrum observed the transit of Venus. He obtained two sets of distance measurements and saw third contact. Also in 1874, James Ludovic Lindsay privately funded an expedition to the same island. Together with David Gill and Ralph Copeland, he set up an observatory at Belmont, the estate of Eduard de Chazal. The day of the transit started cloudy, but soon cleared up to enable observations with the heliometer. The foundations of the observatory have been recovered and the site is now a historic

\footnotetext{
${ }^{3}$ Indeed, each of the major land areas in the Southern hemisphere has a significant observing centre: Chile (Latin America), South Africa (Africa) and Australia. Antarctica has also recently started serving as a launch pad for balloon-borne astrophysical observations (NSF, 2005).
} 
monument. Not far from Port Mathurin on Rodrigues, another island in the vicinity - and part of the state - of Mauritius, a transit observatory hut was erected by Charles Neate on the site of an old fort. The hut was enclosed by a large stone wall to protect it against hurricanes. On the morning of the transit, the observatory was surrounded by police officers and no one was allowed to approach. Neate observed with a 6-inch equatorial. At both ingress and egress, the black drop was very apparent.

Again for the same transit of Venus of 1874, various parties headed to Kerguelen Island (Location: $49^{\circ} 25^{\prime} \mathrm{S}, 6^{\circ} 53^{\prime} \mathrm{E}$ ). Reverend Stephen Joseph Perry and his party set up a chief station at Observatory Bay and two auxiliary stations: one by Cyril Corbet at Supply Bay; the other by Sommerville Goodridge at Thumb Peak. Also on Kerguelen for this event was the German astronomer Karl Nikolai Jensen Börgen and a party of 150 men, who settled at Betsy Cove; and George Ryan, who set up a station at Molloy Point on behalf of the USA.

There were other stations to observe this 1874 transit on such island locations as Nagasaki (Kyushu, Japan), Tasmania, Auckland Island, Chatham Island, Île St-Paul, Nouméa (New Caledonia), Campbell Island, and in Wellington (North Island, New Zealand).

A Dutch expedition ventured to Willemstad, in Curaçao, Dutch Caribbean, for the 1882 transit. Paulus Hendricus Brocx set up his instruments on Fort Nassau in a wooden hut erected for the occasion. During the event, the sky was clear and all four contacts could be timed. George Lyon Tupman successfully observed the same 1882 transit of Venus from Christchurch, New Zealand. While John Robie Eastman set up base at Cedar Key, Florida to observe the transit of Venus for the USA. Another US expedition to Auckland, New Zealand, was led by Edwin Smith ${ }^{4}$.

Almost two centuries earlier, Edmond Halley had visited what is today another UK Overseas Territory. This is St. Helena, then an island possession of the East India Company. Halley observed another transit (this time of the planet Mercury, on November 7, 1677), compiled a catalogue of 341 stars in the Southern hemisphere, and discovered a star cluster in the constellation Centaurus. St Helena was then the southernmost territory under British suzerainty (Longitude: $5.7^{0} \mathrm{~W}$; Latitude $15.9^{0} \mathrm{~S}$ ).

In the $20^{\text {th }}$ century, another Englishman, Arthur Eddington, was dispatched to a remote island to monitor another celestial event, this time a solar eclipse. A gifted mathematician, Eddington led an eclipse expedition in 1919 to Príncipe Island in West Africa: today, this is part of the sovereign state of São Tomé y Príncipe (Longitude: $6.75^{0} \mathrm{E}$; Latitude: $0.3^{0}$ $\mathrm{N})$. In spite of poor weather conditions, the expedition managed to verify the 'bending' of light passing close to the sun as predicted by Einstein's relativity theory. At that time, such observations of stars close to the sun in the sky could only be made during a total eclipse (Coles, 2001).

\footnotetext{
${ }^{4}$ For details on historical records of the transit of Venus, visit: http://www.transitofvenus.nl/history.html.
} 


\section{Easier Spaces to Hive Off}

There remains some clear preference for islands to house Space Stations and Rocket Launch sites. Given their basic geographical characteristics as pieces of land surrounded by water, islands remain more easily circumscribed and under effective surveillance; which is why islands may make such ideal spots for monasteries, refugee camps, prisons, power stations, retreats and holidays. This feature is especially important in today's post 9/11 security-conscious cultures. Kennedy Space Centre in Florida, USA, lies on Merritt Island. Since 1945, NASA's Wallops Flight Facility has launched more than 15,000 rockets from Wallops Island, in Virginia, for science studies, technology development, and as targets for the US military.

\section{Favourable Locations for Rocket Launches}

Given rocket trajectories and the effects of the drag of the Earth's gravity, closeness to the equator is an energetically favourable location for rocket launches. This is fine if one happens to enjoy low latitudes from one's own country, but quite problematic if one does not. This is one key reason why Cape Canaveral, in Florida, is the site of the main rocket launches from the USA (Longitude: $80.6^{0} \mathrm{~W}$; Latitude $28.5^{\circ} \mathrm{N}$ ).

Continental Western Europe, which does not enjoy such conveniently low latitudes, has followed other options. One has been the utilization of one of its members' earlier colonies, geographically located on a different continent. Hence the investment in Kourou, French Guyana, which is the orbital launch site for the European Space Agency and its Ariane rockets (Longitude: $52.7^{0} \mathrm{~W}$; Latitude: $5.2^{0} \mathrm{~S}$ ). Prior to the Kourou development, France used the Kerguelen Islands (Longitude: $70.2^{0} \mathrm{E}$; Latitude: $49.3^{0} \mathrm{~S}$ ) as a sub-orbital rocket launch site for 186 launches from 1963 to 1981 (Wade, 2008).

But 'islands' can also be ingeniously constructed, and towed, to preferred locations. Take, for example, the case of Italy. An industrialized nation with its own space ambitions, an Italian space research program began at the University of Rome in 1959. In 1962, the University signed a memorandum of understanding with NASA to collaborate on a space research program named San Marco (St. Mark). The Italian launch team, trained by NASA, first launched a rocket from Wallops Island under NASA supervision in 1964. From there, the San Marco project was focused on the launching of scientific satellites by Scout rockets from a 'station' located close to the equator. This station, composed of two 'artificial islands' (actually refurbished oil platforms, named San Marco and Santa Rita) along with two logistical support boats, was installed off the coast of Kenya, near Malindi (Longitude: $40.1^{0} \mathrm{E}$; Latitude: $2.9^{0} \mathrm{~S}$ ). Santa Rita was a triangular unit 40 metres wide on each side. It was towed from Italy to Kenya in the winter of 1963-1964 and emplaced in 20 metres of water. The first launches of Nike Apache sounding rockets in the spring of 1964 proved the platform's systems. The San Marco, a 30 x 100 metre rectangle, was emplaced in 1966 and the first Scout launch to orbit came in April 1967. The launch platform complex was in use from 1964 to 1988, witnessing a total of 27 launches. Perhaps the most famous of these launches was Uhuru: the first satellite intended specifically for X-ray 
astronomy, Uhuru was launched from San Marco on a Scout B rocket on 12 December $1970^{5}$ (e.g. Kendrick, 1996).

In the early years of European rocket science, the German island of Usedom, in the Baltic Sea, was the site of a Research Centre which developed and tested various types of rockets, of which two - the V1 and V2 - went into mass production between 1938 and 1944. The first successful rocket launch was from an islet adjacent to Usedom: that of Griefswalder Oie, in December 1937 (Wood \& Ford, 2000: 73; King \& Kutta, 2004: 50). These islands afforded locations away from densely populated regions, clear ranges for rocket testing and relative proximity to their eventual targets in Britain. They could also be more easily guarded and defended from unwelcome encroachment.

\section{Favourable Locations for Emergency Landings}

It used to be ships which made emergency landfalls on opportunely located islands in the past. Now, it is a different type of ship which could benefit from a similar piece of infrastructure. NASA has invested millions of dollars into creating an 'emergency' landing strip for such spaceships as the space shuttle on Rapa Nui (Easter Island) in the South-East Pacific (Royle, 2001: 110-1). The Shuttle Orbiter is authorized to make emergency landing in many countries, including various island locations. There are certified landing facilities in mainland Algeria, Australia, France, Gambia, Germany, Liberia, Morocco, Saudi Arabia, South Africa, Spain, Sweden, Turkey and Zaire, as well as on these island locations: Ascension Island, Canaries, French Polynesia, Crete (Greece), and Britain.

There is, additionally, the 3,650 metre (12,000 foot) runway on Diego Garcia. This island is the largest atoll by land area of the Chagos Archipelago, part of the British Indian Ocean Territory, a UK Overseas Territory. Diego Garcia has been used as a military base by both the USA and the UK, and personnel based there were involved in the recent military invasions of both Iraq (twice) and Afghanistan. The island hosts one of three ground antennas (the others being located on the other islands of Kwajalein in the Pacific Ocean, and Ascension in the Atlantic Ocean) that assist in the operation of the Global Positioning System (GPS) navigational system. The base is part of the US Space Surveillance Network, with a three-telescope GEODSS station, apart from serving as a NASA Space Shuttle emergency landing site.

Regretfully, Diego Garcia is nowadays perhaps best known for the drama of its original inhabitants - some 2,500 Chagossians, or Ilois - who were summarily and forcibly evicted from their homes in order for the UK Government to present a totally depopulated Diego Garcia for use by the American military in 1971. Since their expulsion, the Chagossians have continually asserted their right to return to Diego Garcia (e.g. Winchester, 2004). The US lease on Diego Garcia expires in 2016, but it can be renewed for a further 20 years.

\footnotetext{
5 This nickname was chosen because of the location of the platform and because the satellite launch coincided with Kenya's Independence Day. The word 'uhuru' is Swahili for 'freedom'.
} 


\section{Extreme yet Controlled Habitats}

The simulation of extra-terrestrial environments can be crucial for successful extraplanetary missions in the future. Islands are often the environments that provide approximate weather and/or terrain conditions. The Haughton-Mars Project, for example, is an international interdisciplinary field research project that is unfolding on Devon Island, in the Canadian High Arctic, viewed as a terrestrial analog for the planet Mars. The rocky polar desert setting, geologic features and biological attributes of the island site offer unique insights into the possible evolution of Mars - in particular the history of water and of past climates on Mars - the effects of impacts on Earth and on other planets, and the possibilities and limits of life in extreme environments ${ }^{6}$. Devon Island is now referred to as 'Mars on Earth' 7 . Ascension Island is another place looking much like the surface of Mars; so close is it to that landscape that NASA tested its moon-buggy there.

\section{Virtual Islands}

Finally, islands can be virtual, apart from being material. NASA has set up its own virtual island base - called CoLab Island - on Second Life: an online, three-dimensional, virtual world that is created, shaped, and owned by its participants (Bain, 2007) ${ }^{8}$. Visitors can teleport through the International Spaceflight Museum, where 52 virtual rockets from 12 countries are on display, including a mammoth Saturn 5, a fully loaded space shuttle and the SpaceShipOne rocket plane 9 . Islands, this time of a non-material nature, provide novel spaces where the pursuit of the study of, and fascination with, astronomy can be differently pursued in today's technological age.

\section{Conclusion}

We have attempted a world-wide review of islands and their connections with, and contributions to, astronomy throughout recorded history, up to and including contemporary times. We have not ventured to explore the pivotal role of islands and islanders in the related science of navigation: such is a contribution to science that we acknowledge, but which would be better served by a separate, stand alone paper. We also need to recognize that, dependent as we have been on secondary data, we are limited by what we know and by what we have come across in our limited research pursuits. We are sensitive to the fact that much of this available information is dominated by Western knowledge, and documented by Western scholars: and so, what material we may have located often reads as the exploits and scientific advances of white, male, North Americans and Western Europeans. We recognize this bias and commend initiatives that seek to counter the erasure and relative 'absence of voice' that still afflicts societies and communities (inclusive of

\footnotetext{
${ }^{6}$ More about the Houghton-Mars Project at: www.arctic-mars.org/.

${ }^{7}$ Visit NASA Watch for Devon Island at: www.nasawatch.com/archives/2007/07/earth_as a clas.html.

${ }^{8}$ Second Life is accessible via: http://secondlife.com/.

${ }^{9}$ For more, consult Daily Galaxy at: www.dailygalaxy.com/my_weblog/2007/04/nasa_s_3d_virtu.html.
} 
indigenous peoples), many of whom are citizens of developing countries, and some of whom are located on islands themselves ${ }^{10}$.

With its all too obvious limitations, our review suggests a number of compelling, distinct yet interlocking reasons as to why islands have been and remain so important to astronomy and astronomers. Islands constitute favourable locations for various types of astronomyrelated activities: from tracking satellites to monitoring significant celestial events, from exceptional terrains to jurisdictions with mandated dark and unpolluted skies. Their significance to astronomy has increased with the development of observational instruments and the deployment of spacecraft. Islands appeal both for their favourable longitude and (especially southern) latitude, but also for their disposition towards the conditions that the scientific community may expect in an ideal world: relatively clear viewing conditions from a secure, self-contained platform that is however endowed with connectivity. Most islands share this combination of openness and closure (e.g. Villamil, 1977). Of course, the interests of the scientist can jar or clash with those of island citizens; and the distinction between purely scientific and military pursuits can boil down to a very fine line. Islands are as attractive to military strategists as to scientists, and for basically the same clutch of reasons.

Moreover, the temptation 'to play God' on an island (to the chagrin of any local inhabitants) remains strong. Whether it is Tycho Brahe or the US Military, humankind may have an obsession to control; and so it is not surprising to find a disposition to embrace an island as a finite tabula rasa: a clean slate that is pliable, and liable, to manipulation and encapsulation by human strategy, design or desire (Baldacchino, 2005: 247). After all, just like Robinson Crusoe, "can one be other than a Governor of one's own island" (Redfield, 2000: 12)?

\section{Acknowledgements}

We heartily thank Adrian Galea, Stephen A. Royle, Frank Ventura and other reviewers for comments on an earlier draft. As authors, we accept full and joint responsibility for all errors of omission or commission.

\section{References}

Agius, G. \& Ventura, F. (1980) Investigation into the Possible Astronomical Alignments of the Copper Age Temples in Malta, Malta, Malta University Press.

Bain, B. (2007) 'NASA Launching to Outer Space via Cyberspace', FCW.com, Federal Computer Week, May 31, www.fcw.com/online/news/102852-1.html\#.

\footnotetext{
${ }^{10}$ One such foray is that by Jarita Holbrook on the navigation techniques of fishers from the Kerkennah Islands of Tunisia (Holbrook, 1998).
} 
Baldacchino, G. (2005) 'Islands of Representation', Geografiska Annaler, Vol. 87B, No. 4, pp. 247-251.

Bonanno, A. (author) \& Mintoff, M. (photographer) (1997) Malta: An Archaeological Paradise, Malta, M. J. Publications Ltd.

Christianson, J.R. (1999) On Tycho's Island: Tycho Brahe and his Assistants: 1570-1601, Cambridge, Cambridge University Press.

Coles, P. (2001) 'Einstein, Eddington and the 1919 Eclipse', Historical Development of Modern Cosmology, Conference Proceedings, Vol. 252. (V. J. Martínez, V. Trimble and M. J. Pons-Bordería, eds.) San Francisco CA, Astronomical Society of the Pacific.

Cosgrove, D. (2001) Apollo's Eye: A Cartographic Genealogy of the Earth in the Western Imagination, Baltimore MA, Johns Hopkins University Press.

CSC (2005) 'Small Island Plays Big Role in CSC's Space Work', feature, Computer Science Corporation, www.csc.com/features/2005/34.shtml.

Depraetere, C. \& Dahl, A.L. (2007) 'Island Locations and Classifications' in G. Baldacchino (ed.) A World of Islands: An Island Studies Reader, Canada and Malta, Institute of Island Studies and Agenda Academic, pp. 57-106.

Galea, A. (1994) 'The Leonids of November 13 - 14, 1866, as witnessed from Malta', WGN: Journal of the International Meteor Organization, Vol. 22, No. 6, pp. 200-204.

Holbrook, J. (1998) 'African Astronomy', Essay, Archaeoastronomy \& Ethnoastronomy News Archive, No. 28, June, www.wam.umd.edu/ tlaloc/archastro/ae28.html\#ESSAY.

Kendrick, B. (1996) About Uhuru, www.sonic.net/ nbs/projects/astro305-1/about/.

King, B. \& Kutta, T. (2004) Impact: The History of Germany's V-Weapons in World War II, Cambridge MA, Da Capo Press.

Lanfranco, G. (2005) 'Kurżitajiet dwar 1-Inћawi ta' Tigné' [Curious Facts about Tigné] Tas-Sliema: Leћen il-Kunsill Tiegћek, Sliema, Malta, Issue No 9, pp. 24-25, www.sliemamalta.com/pdf/Issue09(Jul-Sep-2005).pdf.

McCall, G. (1996) Nissology: A Debate and Discourse from Below, 19pp, Sydney, Australia, University of New South Wales, http://southpacific.arts.unsw.edu.au/resources/resource_nissology.htm.

Micallef, P.I. (1992) Mnajdra Prehistoric Temple: A Calendar in Stone, Valletta, Malta, Union Print Co. Ltd.

Micallef, P.I. (1981) 'William Lassell in Malta', Proceedings of History Week, Malta, pp. 108-9. 
Mosley, A. (2001) 'John Donne's Verdict on Tycho Brahe: No Astronomer is an Island?', Studies in History and Philosophy of Science Part A, Vol. 32, No. 3, pp. 583-600.

Murdin, P. (1985) 'Night Time Skies above the Canary Islands', Vistas in Astronomy, Vol. 28, No. 2, pp. 449-465.

NSF (2006) Balloon-based Astronomy in Antarctica, National Science Foundation (USA), http://www.nsf.gov/news/news_summ.jsp?cntn_id=103063.

Orchiston, W. (2004) 'James Cook's 1769 Transit of Venus Expedition to Tahiti' in D.W. Kurtz (ed.) Transits of Venus: New Views of the Solar System and Galaxy, Proceedings IAU Colloquium No. 196, International Astronomical Union, pp. 52-66.

Patrick Air Force Base (2008) Air Force Missile Test Center (Historical). www.patrick.af.mil/art/.

Redfield, P. (2000) 'Robinson Crusoe, Anthropology and the Horizon of Technology' in Space in the Tropics: From Convicts to Rockets in French Guiana, Berkeley CA, University of California Press, pp. 3-26.

Royle, S. A. (2001) A Geography of Islands: Small Island Insularity, London, Routledge.

Tegg, T. \& Curtis, T. (1829) London Encyclopaedia: Or, Universal Dictionary of Science, Art, Literature and Practical Mechanics: Comprising a Popular View of the Present State of Knowledge. Printed for Thomas Tegg. Digitized version at: http://books.google.ca/books/pdf/London_Encyclopaedia_Or_Universal_Dict.pdf?id=c2 tMAAAAMAAJ\&output=pdf\&sig=ACfU3U23up1QpmCpYSN2Vw12tc47tShigg\&source $=$ gbs_summary $r \& c a d=0$.

Thoren, V.E. (1990) The Lord of Uraniborg: A Biography of Tycho Brahe, Cambridge, Cambridge University Press.

Ventura, F. (1990) 'Grand Master de Rohan's Astronomical Observatory (1783-1789)', Melita Historica (New Series), Vol. 10, No. 3, pp. 245-255.

Ventura, F. (2002) L'Astronomija F'Malta, Malta, Publikazzjonijiet Indipendenza.

Ventura, F. \& Tanti, T. (1999) 'Sunspot Cycle 22: A Qualitative and Quantitative Analysis', Journal of the British Astronomical Association, Vol. 109, No.4, pp. 32-37.

Villamil, J. J. (1977) 'Size and Survival: Planning in Small Island Systems', Microstate Studies, No.1, pp. 1-7.

Von Klüber, H. (1968) 'The Cambridge University Solar Research Station in Malta', Solar Physics, Vol. 4, No. 4, pp. 479-488. 
Wade, M. (2008) Kerguelen. Astronautix.com. www.astronautix.com/sites/keruelen.htm.

Winchester, S. (2004) Outposts, Journeys to the Surviving Relics of the British Empire, New York, Harper Collins.

Wood, P. \& Ford, R. (2000) Germany's Secret Weapons in World War II, Slovak Republic, MBI Publishing. 